Transportation Research Forum

Credit-Based Congestion Pricing: Expert Expectations and Guidelines for Application Author(s): Pradeep K. Gulipalli, Sukumar Kalmanje, and Kara M. Kockelman

Source: Journal of the Transportation Research Forum, Vol. 47, No. 2 (Summer 2008), pp. 5-19

Published by: Transportation Research Forum

Stable URL: http://www.trforum.org/journal

The Transportation Research Forum, founded in 1958, is an independent, nonprofit organization of transportation professionals who conduct, use, and benefit from research. Its purpose is to provide an impartial meeting ground for carriers, shippers, government officials, consultants, university researchers, suppliers, and others seeking exchange of information and ideas related to both passenger and freight transportation. More information on the Transportation Research Forum can be found on the Web at www.trforum.org. 


\title{
Credit-Based Congestion Pricing: Expert Expectations and Guidelines for Application
}

\author{
Pradeep K. Gulipalli, Sukumar Kalmanje, and Kara M. Kockelman
}

Congestion pricing $(\mathrm{CP})$ ensures that travelers recognize the true travel-time costs of their tripmaking by accounting for the cost of delays imposed on fellow road users. Credit-based congestion pricing $(C B C P)$ is a novel strategy which seeks to overcome the negative equity impacts of $C P$ by allocating monthly budgets to eligible travelers to spend on congestion tolls. Previous works on $C B C P$ have surveyed public opinion and examined the traffic and travel-welfare impacts of an Austin, Texas, application. This paper develops the $C B C P$ policy further, examining expert opinions and system cost prediction. Transport economists, toll technology experts, administrators, policymakers, and commercial interests were surveyed for feedback on credit distribution, revenue uses, public reaction, appropriate technology and configuration, enforcement issues, and system-wide economic, land use, and business impacts. The results of this work are detailed recommendations for $C B C P$ implementation, including estimates of administrative and technology costs for implementation of a $C B C P$ policy in the Austin region.

\section{INTRODUCTION}

Transportation policy development can be viewed as an objective dialogue between the public who are the major stakeholders, various interest groups who lobby for or against the policy, and the administrators who guide regional development. Also, the implementation and refinement of any significant transportation policy requires an understanding of the policy's systemic impacts on traffic, land use, air-quality related costs and benefits, and likely stakeholder opinion. Through their expert opinions, transport economists, planners, and technologists can provide valuable contributions to the transportation policy development process. One such transportation policy in need of expert opinions for further development is credit-based congestion pricing (CBCP) (Kockelman and Kalmanje 2003).

By ensuring that travelers recognize the true travel-time costs of their trip-making (by accounting for the cost of delays imposed on fellow road users), congestion pricing (CP) has proven to be an effective congestion management policy. Even though CP has the potential to benefit society as a whole, it can adversely affect certain user groups (e.g., low-income users and commuters with little or no work flexibility). $\mathrm{CBCP}$ is a congestion management policy which seeks to overcome the negative equity impacts of CP by allocating monthly budgets to eligible travelers in a priced region to spend on congestion tolls. This work sought to identify and isolate expert perspectives on CBCP budget allocation, equity issues, economic, land use, and business impacts, revenue uses, and toll collection. These were reviewed to produce recommendations for the implementation of a CBCP policy. Cost estimates for such a policy also are provided.

\section{MOTIVATION AND LITERATURE REVIEW}

Since CBCP seeks to overcome CP's negative equity impacts by providing travel budgets (Guiliano 1994, Elliasson and Mattsson 2006), a closer examination of equity issues and other impacts is required to develop implementation guidelines. In a congested region, $\mathrm{CP}$ has the potential to transfer a great deal of money from the traveling public to toll collecting authorities. While a certain portion of such revenues is needed to cover the costs of a CP program (paying for items such as roadside detection devices, variable message signs, toll collection, and general program administration), the 
rest arguably belongs to "the public" who paid for the road's construction and its operation via taxes. Hence, such revenues should be used to compensate the users (directly or indirectly). Of course, if users are compensated in proportion to how much they pay or how much they drive, there is no incentive to change one's travel behavior. Paying a higher amount to users who drive more (and hence pay more) or have higher vehicle ownership actually provides an incentive for people to drive more or own more vehicles, which is not desirable.

Past research has looked into various revenue distribution strategies. For example, Small (1992) proposed a travel allowance for all commuters. He recommended a fixed amount per month per employee regardless of mode or time of travel so that CP incentives (i.e., reduced driving on congested roads) would not be undermined. Taking a different approach, Parry and Bento (2001) recommended that income taxes be reduced to offset any CP-related labor supply restrictions. To offset several CP impacts, Goodwin (1989) and Small (1992) suggested combinations of revenue uses.

Under standard CP, few travelers may benefit sufficiently from the resulting travel time savings to appreciate the policy. This is particularly true in the short run due to fixed home, work, and school locations (see Arnott et al. 1994, Parry and Bento 2001). Though CP may have the potential to benefit society as a whole (i.e., Pareto improving), it can adversely affect certain user groups (e.g., low-income users and commuters with little or no work flexibility). Researchers have tried to address this issue of offsetting CP's adverse effects while maintaining certain behavioral incentives. Gee and Hannemann (2002) proposed compensation for people negatively impacted by CP in the same "dimension" as the impact (such as free weekend parking for those less able to pay weekday tolls). Dial (1999) recommended always providing a "free" route, via minimum revenue CP. DeCorlaSouza (2000) suggested toll credits for regular drivers via FAIR (Fast and Intertwined Regular) Lanes. And Viegas (2001) proposed providing a certain level of "mobility rights."

A CBCP policy, as conceived by Kockelman and Kalmanje (2003), has the potential to allay these equity concerns. According to the policy, every eligible traveler (e.g., every licensed driver living in the designated "priced region") may be given a monthly travel budget. Those in the driving population who exhaust their travel budget while paying congestion tolls will pay out of pocket to keep driving, while those who save their travel budget can cash this out as a direct monetary saving. Each month's travel allowance depends on the total revenue collected during that (or the previous) month. Revenue neutrality is maintained by returning all revenues, after covering policy administrative costs. According to a survey reported by Kockelman and Kalmanje (2003), Austin, Texas, residents found such a policy to compete reasonably well with transportation policy alternatives. In a different paper, Kalmanje and Kockelman (2004) predicted Austin area trip-based welfare impacts and land value changes under two different CBCP scenarios. They predicted CBCP to benefit most residents, whereas standard $\mathrm{CP}$ (without revenue redistribution) benefited relatively few. For Austin, a CBCP policy with all roads priced according to marginal delay costs was expected to return around $50 \notin$ per user per day. They also predicted a small overall drop in residential property values when CP was imposed on all roads, and a small rise in downtown property values when imposing CP only on major highways. Credit-based CP could be expected to cause greater property value increases because of the inherent rebate.

Recognizing CBCP's potential as a viable and equitable congestion management strategy, this paper explores the policy in further detail, and refines it based on opinions of transportation experts, policymakers, stakeholders, and special interest groups. Authorities may wish to invest the revenues in a variety of ways; hence, several alternative uses for CBCP revenues have been studied. A thorough review of implementation costs has been undertaken and a set of implementation guidelines has also been developed. 


\section{METHODOLOGY}

To begin, an extensive survey of experts and special interest groups was undertaken to study and obtain opinions of a hypothetical regional CBCP implementation. These respondents included academicians and practitioners in the field of transport economics, toll technology, administration and policy, and commercial users of the transportation system. Four survey forms were used for these distinct respondent groups. Respondents were asked to predict system impacts and voice their concerns and suggestions for implementation. The questionnaires for the economists, policymakers, toll technologists and commercial users were mailed in February 2004 to 180 people, of whom 50 responded after multiple follow-ups (including e-mails and phone calls). These included 19 transport economists, 10 policymakers (all from Texas), nine toll technologists, and 12 commercial users. Based on the survey results, guidelines for CBCP implementation are suggested. Several enforcement issues also have been resolved, and cost estimates for CBCP toll technology, system operation and administration are provided for the Austin region.

\section{RESULTS: SYNTHESIS OF EXPERT PERSPECTIVES}

This synthesis of respondent perspectives first discusses the $\mathrm{CBCP}$ equity issues raised by the respondents, their initial impressions of the policy, and their suggestions to make it more effective. It then describes predicted economic impacts and land use changes, commercial user reactions, and anticipated business impacts. Respondents' concerns over CBCP, opinions on revenue use and their expectations of public reaction to the policy are presented. Finally, experts' recommendations for technology, dynamic pricing, and data requirements are compiled. Not all topics were answered by the respondents. Some statements in the following pages are suggestions of some respondents, and it is difficult to determine the opinions of the rest of the respondents about these suggestions. In such cases, it is not possible to provide descriptive statistics (proportion of respondents in favor of or against an idea). However, descriptive statistics on some overall opinions are provided, wherever appropriate, and are summarized in Table 1.

Table 1: Descriptive Statistics on Expert Opinions about CBCP

\begin{tabular}{lcc}
\hline & Number of Responses & $\%$ Supporting \\
\hline Clear equity benefits & 12 & $75 \%$ \\
Effective and economically efficient & 12 & $75 \%$ \\
Attractive features & 13 & $85 \%$ \\
Land use benefits & 14 & $86 \%$ \\
Positive effect on local economy & 13 & $85 \%$ \\
\hline Advocate road pricing (CBCP/others) & 13 & $92 \%$ \\
\hline
\end{tabular}

\section{Budget Allocation and Equity Issues}

The transport economists expressed concern over so many possible people getting a travel budget, whether or not they used the priced corridors. Some did not find it fair for everyone with a driver's license (e.g., high school students, people who rarely need to drive) to receive a travel budget. And some felt that differential budget allocations would make CBCP more of a welfare program - and that transportation policies are not efficient for income redistribution.

There was a variety of feedback on issues relating to the policy's equity. The transport economists considered departure time flexibility and value of time to be important factors in determining the policy's benefits for any specific individual. Office workers and others having to travel during peak periods would be most negatively affected, while those traveling at off-peak hours would benefit (e.g., non-workers and industrial shift employees). Some policymakers and commercial users felt that 
people living in certain zones could be disadvantaged since alternatives to peak-period solo driving are not the same in all zones. (For example, public transit does not serve all neighborhoods.)

Several transport economists suggested that low-income people traveling longer distances to work would be adversely affected, especially those who choose low-cost housing away from activity centers. So allocating an equal travel budget to everyone might leave low-income people less well off than before the policy was implemented. However, this depends on the number of lowincome drivers during congested periods, the number who would qualify for a travel budget, and the availability of alternative travel modes. A similar opinion was expressed by some policymakers (25\%) who mentioned that current inequities (e.g., access to facilities and jobs) may be magnified under CBCP. However, some respondents opposed any budget allocation that would be based on income. They felt that verifying income would be administratively burdensome and would create an opportunity for significant fraud. All four respondent types were of the opinion that budget allocation per-adult-resident would benefit the presently disadvantaged while allocation per-registered-vehicle would reward vehicle ownership (and thus benefit the well-off).

\section{Economic Impacts and Land Use Changes}

The majority of respondents (85\%) thought that $\mathrm{CBCP}$ would stimulate the economy. However, some did not expect any noticeable changes, and a couple suggested that CBCP might actually dampen the economy. If the strategy is accepted by the public and resolves congestion problems, then it should benefit the local economy. However, an improved economy potentially could increase travel demand and exacerbate congestion. If capacity expansion is not required, the government might invest a portion of CBCP revenues elsewhere, which also could be good for the economy.

Almost all respondents (85\%) predicted more compact land development if CBCP was implemented, thus decreasing sprawl, while others did not expect any land use changes. They did expect location and travel demand shifts though: People would have an incentive to move closer to jobs, carpool, and travel off-peak, thus decreasing peak travel (Kalmanje and Kockelman 2004). Respondents expected an increase in the demand for transit-oriented development and a decrease in the long-run demand for additional highway capacity. Some predicted housing to become more centralized and employment less centralized. Respondents suggested that businesses based in the Central Business District (CBD) would become less attractive compared to those in suburban sites since accessing the CBD would become costlier ${ }^{1}$. A CP policy was expected to have impacts similar to that of a CBCP policy, as described above, and the extent to which these impacts differ would depend on the way each policy is implemented (e.g., budget allocation and pricing policies).

\section{Commercial Users’ Perspectives and Predicted Business Impacts}

While potential benefits to less congestion were expressed, most commercial users appeared uninterested in the benefits that their region's transportation and distribution systems might see, and instead were interested in personal disadvantages from such a program (for instance, increased costs of solo commuting). This response may reflect the growing reliance of businesses on other companies, such as shippers and couriers, for transportation and distribution. As outsourcing of transportation and distribution become more ingrained in business models, incentives for timely delivery no longer reside so much in these commercial entities but in their shippers and couriers. This trend may undercut incentives that reduced congestion levels might have otherwise provided to many commercial users.

Those who depend heavily on timely product and service deliveries indicated a clear willingness to pay a premium to guarantee such deliveries. Office-based employers were willing to support some congestion mitigation policies, as part of an effort to reduce regional pollution. There was very little interest in subsidizing employee-related $\mathrm{CBCP}$ costs. A common perspective seems to be that employees must plan to get to work on time irrespective of where they live. Also, any flexibility 
or company policy changes (in their respective firms) caused by $\mathrm{CBCP}$ would be slow to come since decisions regarding flex-time and toll-reimbursement ultimately would have to come from a firm's corporate headquarters. Interviewed employers stressed that they already offer or are most likely would offer a flex-time workday option. If customer levels increased during a certain time of day due to $\mathrm{CBCP}$, several of the service-centered businesses said that they would change staffing hours to accommodate the variation in customer volumes.

\section{Concerns about CBCP}

Respondents were asked to rank CBCP issues that most concerned them. Unranked alternatives were assumed to not pose a serious concern for the respondents. The major concern for most transport economists $(50 \%)$ was the proposed uniform allocation of travel budgets to all possible roadway users. For example, the respondents felt that commuters, retired persons, and high school students have different needs and should be provided different travel budgets. Similarly, low-income people might be more adversely affected than high-income individuals and may need higher budgets. Another issue mentioned was the policy's administrative cost burden. Privacy and technological feasibility did not seem to be major issues. Those with privacy concerns do not appear to trust the government because it would then have one's trip information. Others were more concerned about political feasibility, traffic impacts, and land use impacts. Some of the economists also expressed concern about traffic spillovers onto non-priced streets. The policymakers brought up the issue of the agency that would be needed to administer such a system. Since CBCP could apply region-wide, its administration would extend beyond the municipal level, possibly via the power and guidance of Texas' Regional Mobility Authorities and complicate revenue handling. Spillover onto some local streets (to avoid tolls) may adversely impact some locations, which may demand some of the collected revenues to improve their own infrastructure. Smaller communities beyond the region's fringe may lobby for admission to the policy region, if their residents are not given travel budgets. Such concerns may make revenue-neutrality a difficult goal to achieve.

\section{Alternative Revenue Uses}

Transport economists were asked to rank a set of alternatives for uses of "excess revenues" from a CBCP implementation even though the Kockelman and Kalmanje (2003) CBCP proposal aimed to be revenue neutral through issuance of travel budgets. Any unranked alternatives are assumed to hold the lowest ranking. Most $(60 \%)$ wanted such revenues to go toward maintaining existing infrastructure and/or to adding capacity. Next was the development of alternative modes such as transit. Those who strongly favored transit (50\%) were not interested in reducing gas taxes - and vice versa. Some respondents $(20 \%)$ suggested reducing general taxes via CBCP revenues. There was not much interest in using such revenues to improve air quality.

The question of revenue use was approached cautiously by policymakers, all of whom are from Texas. There were references to Texas HB35882, which went into effect in September 2003 with very specific guarantees regarding application and use of standard road tolls. The contacted policymakers felt that Texas toll revenues must be used to cover the construction costs of new transportation infrastructure, much like toll revenues from IH-30 between Dallas and Fort Worth were used many years ago.

\section{Public Response: Expert Opinions}

There were concerns about the best way to propose CBCP since any restrictions on mobility are bound to generate controversy. A simpler policy, to start with, might find greater public acceptability. For example, people who are not exposed to flat tolling might not be very comfortable with a CBCP policy. All policymakers felt that public acceptability could be rather low despite the logic of CBCP's 
design and the congestion-reduction benefits the public would experience. However, the transport economists felt that CBCP could be more acceptable than other pricing strategies. There is some research and practical evidence to support that argument. Kockelman and Kalmanje (2003) found public support for CBCP in Austin (24.9\%) to be similar to that for flat tolling (24.2\%). Support for $\mathrm{CBCP}$ was higher (50\%) among persons already familiar with $\mathrm{CP}$. Thus, education may be the key to generating popular acceptance. London is an example of increase in CP's public acceptability following people's exposure to that city's cordon toll.

The experts were asked whether collecting non-congestion-related tolls (to finance infrastructure) together with CBCP might create any problems. The general response $(80 \%)$ was that the public will need to be educated about the redistribution of congestion toll revenues (as travel budgets) versus the use of infrastructure tolls for roadway maintenance and improvements. Some respondents (30\%) were apprehensive that introducing too many tolls at once might confuse the public. A suggestion involved replacing the gas tax with a flat toll and introducing CP in the form of off-peak and lowuse road discounts, so as to increase public acceptability. Another was that infrastructure toll was likely to be much larger than a simple replacement of the current gas tax. Suggestions hinted at using standard $\mathrm{CP}$ as a means of financing new infrastructure, delaying the implementation of CBCP until the initial investment is recovered. But, such a strategy has associated equity problems (e.g., why should only peak-period users be charged), and maintenance costs remain significant.

When participants were asked about the preferred pricing policy (including $\mathrm{CBCP}$ ) for their region, High Occupancy Toll lanes emerged as the favorite primarily due to public acceptability and political feasibility. CP was also a prominent choice, but some respondents indicated that CBCP could be a better option considering its potential to gain greater public support. Flat tolls could be implemented before CBCP, so as to increase public awareness/acceptability. Other responses included flat tolls, managed lanes, ramp metering, FAIR lanes, parking charges and area-wide roadway pricing (like in London). Flat tolls on a portion of the network may prove a useful transition policy for CBCP across the remaining network's principal corridors.

\section{Electronic Toll Collection (ETC) Technology and Configuration}

Toll technology experts across the U.S. responded to a series of technology and CBCP-related questions. Experts recommended technologies that could function over a wide range of frequencies/ protocols. Modular technologies were advocated, so that the latest modules could be incorporated as needed. Based on the survey responses and current ETC implementations, we recommend Radio Frequency (RF) tags for their easy availability and cost effectiveness. GPS was another popular choice considering it could become a common technology in future vehicles. However, skepticism existed following problems with the stability of on-board units in Germany's truck tolling program, 'TollCollect' (TOLLROADSnews 2003). Some recommended dedicated short-range communications (DSRC) transponders, but an ETC company representative indicated that such transponders cost hundreds of dollars while new RF tags cost as little as \$5-\$10 each. Automated number plate recognition (ANPR) technology was the choice for enforcement. This technology uses cameras to photograph the license plates of vehicles that fail to relay usable tag identification. Information regarding the owners of such vehicles could be obtained from the state's vehicle registry. The major problem with ANPR is some inaccuracies that require manual verification such as lack of plate standards, dirty and damaged plates, incorrect plate mounting, differences in vehicle design and plate position, and ambiguity/similarity in letters/numbers ${ }^{3}$.

Respondents recommended placing ETC units at freeway entrances and exits unless such ramps are rather frequent (i.e., every two miles or less). In that case, placing antennas/readers at two to four mile intervals might be more cost effective. Placing antennas/readers at entrance and exit ramps (on an access-controlled highway) would involve fewer transactions; but, if one of the readings is flawed or missing, the trip record is lost. Frequent antennas (readers) involve more transactions and even if data from one reader is missing, those from others can be used to determine the appropriate 
toll. The cost estimation analysis assumed that ETC units are spaced every three miles (on average) along freeways. Respondents felt that dynamic pricing (where tolls vary with traffic levels) can be implemented despite concerns over unpredictable toll levels. While marginal cost pricing (MCP) of roadways, as a function of traffic levels, is theoretically the best, such dynamic pricing adds uncertainty to travel options and may not be tenable. Some balance between pre-determined tolls (by time of day) and flexible tolls may be best in practice, as done in the case of SR91 (Orange County Transportation Authority 2003). To increase acceptability, provision of alternative nonpriced routes and appropriate positioning of variable message signs (VMS) boards were suggested.

\section{Issues with User and System Data}

When policymakers and toll technologists were queried about user data issues, the majority of policymakers $(90 \%)$ seemed comfortable using vehicle license information from state records as needed. Some toll technologists (50\%) suggested storing credit card information (so as to automatically replenish accounts with cash credits). Those against it (25\%) cited the possibility of fraudulent use of such information and unease over being automatically billed for a dynamically priced product. Both groups also were concerned that people might not trust the government with their credit card information; hence, a third party might be needed for this purpose. Irrespective of the type of information stored, respondents (75\%) felt that data storage would be very burdensome. For example, keeping track of the thousands of people moving into and out of the region each month would be "untenable." Respondents felt that Social Security number information should not be needed. Respondents suggested that a customer service center would be needed to handle problems regarding faulty tags, incorrect billing, account information and corrections, and other credit dealings.

\section{Overall Opinion of CBCP}

Many respondents ( $85 \%$ of transport economists, toll technologists, policymakers, and commercial interests) expressed concern over the level of administrative costs needed for a CBCP policy implementation. Transport economists extended support for CBCP since it employs market signals (prices) to allocate scarce resources (highway capacity) resulting in more effective infrastructure use. A majority of experts agreed that $\mathrm{CBCP}$ is more effective than flat tolling and normal $\mathrm{CP}$. All policymakers that responded to the survey felt that $\mathrm{CBCP}$ would ease traffic congestion in their regions. Many acknowledged that user fees are becoming increasingly common in municipal and state operations. Several transport economists seemed comfortable with the policy and its equity implications. Commercial users seemed to appreciate the policy for its contribution to more reliable travel times. The responses from toll technologists suggest that CBCP is technologically viable.

\section{RECOMMENDATIONS FOR IMPLEMENTATION}

Based on all expert responses, the results of a prior survey work (Kocklemman and Kalmanje 2003) and thoughtful consideration of all reasonable policy options, a set of guidelines have been developed for CBCP application. These address issues pertaining to practical trade-offs in budget allocation, enforcement, and administration. Network pricing for CBCP policy could be implemented in many ways. Since the cost of pricing all roads in a region with today's technology is estimated to be prohibitively high, pricing only the major, congested corridors may be the most feasible implementation option, at least at the start. Roads that suffer from significant CBCP-related traffic spillovers also could be priced. The recommended policy is as follows:

A CBCP policy provides all eligible travelers with a travel budget to spend on congestion tolls using a transponder account linked to their names. Ideally, marginal cost pricing for delays induced by added road users would be imposed on all major congested roads, and the net revenues 
would provide for these monthly travel budgets. Without system-wide roadway pricing, the optimal tolls will not reflect true marginal delay costs since many non-priced (yet congested) routes are still available between origins and destinations. For efficient system operation, all complementary and substitute routes must be appropriately priced. Any budget not spent by the end of the month may or may not, depending on the chosen policy, serve as a cash savings or credit to the account holder. Those exceeding their budgets have to pay for any additional tolls out of pocket. Kalmanje and Kockelman (2004) provide estimates of total revenues and average travel budgets for a $\mathrm{CBCP}$ implementation in Austin. As originally conceived, the policy was meant to be revenue-neutral in that all revenues collected each month were to be distributed among all qualifying drivers in the region, after covering system administrative costs. In practice, the actual chosen policy may differ. Returning cash to participants is an incentive for fraudulent activity (via ineligible persons claiming eligibility) that can be difficult and costly to regulate. In light of expert caution and concerns regarding the administrative burdens of the originally conceived policy, several changes were made in constructing the final policy recommendations.

\section{Toll Tags}

All system users should be able to obtain transponders for their vehicles upon paying a refundable deposit. Users of IH 15's FasTrak lanes (in San Diego) and users of Dallas-Fort Worth toll roads presently pay a refundable deposit of $\$ 40$ to obtain a transponder. However, if low-cost tags ${ }^{4}$ are used, the users could be asked to buy their own tags. The transponders will be associated with unique, vehicle-specific accounts ${ }^{5}$ that hold user data such as name, vehicle license plate number and/or a unique ID number, user address (available from vehicle registration records), and credit card information (required only if a user chooses to pay tolls using his/her credit card). Because travel credits/budgets are involved, $\mathrm{CBCP}$ involves more personal data collection than a $\mathrm{CP}$ application. Additional information could be stored based on the methodology adopted to identify people eligible for a travel budget. For example, if budgets are to vary as a function of corridor use such data could be kept. In addition, budgets may only be granted when sufficient identifying information is presented, such as documents proving the vehicle is insured and registered in the region of CBCP application.

\section{Travel Budget Eligibility}

One of the most difficult decisions and implementation issues associated with a CBCP policy is that of budget eligibility and distribution. The two most likely criteria for eligibility are based on use of priced roadways and on location of residence. Both approaches have strengths and limitations - as well as several variations. A user-based criterion (based on a minimum number of miles or days driven, for example) seems most relevant in a region where relatively few roadways are priced, so that those who really need the corridor are identified through use. A residence-based criterion works best when a well-defined region's network is extensively priced; and residents of different locations may be eligible for different levels of travel budgets, depending on the expectation of need and/or contribution to the network's provision (via property taxes, for example).

Different budget-eligibility criteria and their associated limitations were considered such as allocating budgets only to registered vehicle owners versus all licensed drivers in a region. The potential for fraudulent representation of use and/or residence is what led to the strategy recommended here: travel budgets are best tied to a vehicle (based on its use or its registration address), rather than to an individual's transponder (which can be shared easily with others). Drivers' own transponders also can be read, in addition to vehicle identification tags, but that would require additional investment in technology. So the final recommendation is for transponders attached to vehicles. Only licensed vehicle owners with registered vehicles would be eligible for travel budgets. Individuals can be 
asked to share their insurance records in order to become eligible for a travel budget, thus reducing incidence on uninsured motorists.

Those owning more than one vehicle would be eligible to receive only one travel budget. Of course, people could still register their vehicles under the names of licensed family members and others, and people might retain older and more polluting vehicles just to obtain additional budget. However, vehicle licensing, registration, insurance, inspection, and maintenance costs are likely to substantially exceed base travel budgets in most regions, particularly where revenues are largely reserved for use toward transportation system expansion and enhancement. It is unlikely that people would retain old polluting vehicles to obtain budgets since the cost of titling and registration would exceed the budget.

\section{Treatment of Visitors}

Toll technology experts indicated that enforcement is usually not easy if both ETC users and nonusers use the same corridor. This could very well happen in a CBCP scenario since visitors (drivers) to the system may not have readable transponders. One option is to let visitors drive for free. This would require the system to keep track of such vehicles (via ANPR) so that fines are not pursued. Ideally, visitors would be required to purchase a 'day pass' to use the priced corridors. Melbourne, Australia's CityLink program has a similar daily pass option for its users (CityLink 2004). Visitors would be asked for their vehicle license plate information on purchase of a day pass, which could be bought online or at a roadside store as in London's cordon toll application (Transport for London 2008). Vehicles without transponders, which use the priced corridors, would be detected by ANPR. And vehicles tied to a purchased 'day pass' would be removed from the violator list at day's end.

\section{Budget Distribution}

In general, the same budget level may be granted to everyone. However, if equity is a key consideration, multiple budget levels may be useful. Budget levels could be based on employment status and household income. People with special needs could apply for a higher budget. If budget eligibility is determined by residence location then different packages/discount programs could be designed for people residing outside the CBCP budget eligible zone. For example, users of SR91 express lanes can opt for one of the four available account types: 91Express Club, Standard plan, Convenience plan, and Special access.

It should also be noted that if eligible people receive their monthly budgets on the same day, choice behaviors regarding when to spend one's travel budget could result in undesirable traffic patterns depending on time of the month. People might drive initially and then shift to transit as they run out of travel budget, creating a temporary high demand for transit services (and low demand for road space). To prevent such fluctuations, revenue distribution should be staggered.

\section{Record Management}

Every user would have an online account (updated daily) to access all charges, credits, and other account information. Tolls and any fines would be charged to users' accounts and would be accessible (and contestable) online. If payment is not received within a certain grace period, the state police could issue a citation (as in the case of North Texas Tollway Authority's Tolltag users in the DallasFt. Worth region). Use of pre-paid accounts and automatic deposit options can ensure balances remain positive. 


\section{Credit Controls}

As originally conceived, CBCP involves a monetary transaction (in the form of a travel budget that can be accumulated and used to purchase other goods) from the managing agency to all travelers including those without vehicles. Such an approach provides a relatively strong incentive for fraud (where ineligible persons claim eligibility) - along with administrative burdens and significant enforcement costs. To avoid such issues the budget can be linked to locally registered (and insured) vehicles, and individuals would not be permitted to accumulate - or cash out - their travel budgets.

By not returning all revenues in the form of cashable budget system, managers can retain a portion of revenues for alternative uses. And, by keeping travel budgets low (relative to revenues) and tied only to registered and licensed vehicle owners, fraudulent representation of eligibility becomes less of an issue and more revenues become available for alternative uses. The uses most popular among experts surveyed are maintaining existing roads, adding capacity, and investing in alternate modes like transit. Of course, a region's stakeholders and policymakers can make their own determinations. In some regions, transit subsidies may be most desirable; in others they could be new expanded bridges and removal of bottlenecks.

\section{Cost Estimates}

Estimates of initial investment and recurring costs are required to predict net revenues. The paper computes the one-time investment costs based on the cost estimates provided by USDOT. The North Texas Tollway Authority's (NTTA) administrative expenditures for the financial year 2003 were used to estimate operations and management (O\&M) costs for an Austin, Texas, CBCP. To assume that all freeways would be priced is conservative since not all freeways are congested. Austin has 105 centerline miles of roadway (measured via the centerline) and 570 lane miles of freeways, which are the sum of centerline miles times number of lanes (USDOT 2000c), 55\% of which are congested (Schrank and Lomax 2003) in that conditions do not allow travel at the posted speed limits of 60 mph on freeways and $35 \mathrm{mph}$ on major streets. The following analysis assumes that fully $75 \%$ of the Austin freeway network is priced, making it a conservative cost estimate.

\section{Initial Costs}

Two USDOT reports (USDOT 2000a and 2000b) give the range of costs for toll plaza equipment and toll administration equipment used here to estimate total initial costs. Assuming one toll plaza for every three miles (as suggested by toll technology experts) requires around 27 toll plazas. Since only one structure is assumed for all the lanes at any point, the estimate uses the higher USDOT estimate for mainline structure. Since there are multiple lanes at each plaza, 150 electronic toll readers are required (one reader per lane). Around 100 high-speed cameras would be required (one for every two lanes, to ensure violation detection (USDOT 2000a). It is expected that users would cover their transponder costs by purchasing the tags or by paying a deposit, as appropriate.

As mentioned earlier, the latest transponders like eGo ${ }^{\mathrm{TM}} 2201$ (TransCore 2002) cost less than $\$ 10$ per tag. The initial cost is estimated to be $\$ 11.4$ million (Table 2), which amounts to about $\$ 9$ per Austin resident. Readers should note that Austin's MPO, the Capital Area MPO (CAMPO), recently approved a $\$ 2.2$ billion toll road plan for the region. Initial CBCP cost estimated here for transponders (which represent $84 \%$ of all initial costs) should overlap with toll road plan costs. 
Table 2: Initial Technology Cost Estimates for a CBCP Application in Austin, TX

\begin{tabular}{lrrr}
\hline One-time investment & Unit Cost & No. of Units & Total Cost \\
\hline ETC structure & $\$ 15,000$ & 27 & $\$ 405,000$ \\
ETC software & 7,500 & 27 & 202,500 \\
ETC readers & 3,500 & 150 & 525,000 \\
High speed cameras & 7,500 & 100 & 750,000 \\
Toll administration hardware & 12,500 & 1 & 12,500 \\
Toll administration software & 60,000 & 1 & 60,000 \\
Toll tags & 10 & $945,500^{\text {a }}$ & $9,455,000$ \\
Total cost & & & $\$ 11,410,000$ \\
\hline
\end{tabular}

a This is the number of vehicles in Austin, where average vehicle ownership is 1.81 vehicles per household (as taken from Austin's travel survey of households) and the projected number of households for the year 2003 is 522,372 (United States Census of Population 2000).

${ }^{\mathrm{b}}$ All cost estimates are in constant 2003 US dollars.

\section{Recurring Costs}

Operating expenses for the NTTA (2003), New Jersey Turnpike Authority (2003), and San Joaquin Hills Transportation Corridor Agency (2003) were used to arrive at system costs of an ETC application in Austin. Table 3 shows the calculated expenses per lane mile. Depreciation and amortization expenses were excluded since they result from financing decisions. Manual toll collection costs, state police, snow removal, and toll-tag pre-payment expenses also are not included, since they are not recurring costs for an Austin CBCP application.

Table 3: Recurring (Annual) Cost Estimates of Various ETC Projects

\begin{tabular}{lrcc}
\hline Toll Road Program & $\begin{array}{c}\text { Operating } \\
\text { Expenses }\end{array}$ & $\begin{array}{c}\text { Lane-Miles of } \\
\text { Toll Roads }\end{array}$ & $\begin{array}{c}\text { Expenses per } \\
\text { Lane-Mile }\end{array}$ \\
\hline NTTA & $\$ 32,553,600$ & 313 & $\$ 104,005$ \\
NJ Turnpike Authority & $\$ 140,023,307$ & 1,219 & $\$ 114,867$ \\
San Joaquin Hills & $\$ 9,530,000$ & 108 & $\$ 88,241$ \\
\hline
\end{tabular}

Since a CBCP application is very similar to a standard ETC application, its operating costs can be assumed to be comparable to ETC operating costs. One major distinction arises from maintaining CBCP travel budget accounts. Maintaining such accounts involves creating and verifying budgets and an additional secure record keeping. Thus, it involves personnel from the legal, audit, accounting and community affairs departments. Therefore, the corresponding NTTA expenses were doubled, resulting in a cost "cushion" of 9.1\% over a regular ETC facility.

CBCP operating expenses per lane mile are estimated at $\$ 113,569$ per year, or a total of $\$ 48.5$ million for the Austin region annually. This corresponds to $\$ 38.10$ per Austin resident. In comparison, Austin residents are estimated to experience an average annual congestion cost of $\$ 590$ (per resident), which includes delay and fuel costs on all congested roadways (Schrank and Lomax 2003). The daily vehicle miles traveled on freeways and other major roads and the percentage of peak period person-trips that are congested (Schrank and Lomax 2003) were used to estimate that around $75 \%$ of the congestion costs in Austin are on freeways (assuming similar congestion levels on freeways and other traveled roadways). This is equal to $\$ 442.50$ per Austin resident. The total cost per resident obtained by applying a capital recovery factor to the initial cost equals $\$ 39.30$. $^{6}$ Annual investment of $\$ 39.30$ per resident seems reasonable to address freeway congestion. These cost calculations appear to support the case for CBCP as a worthwhile congestion mitigation strategy in a region like Austin. 


\section{CONCLUSIONS}

Kalmanje and Kockelman (2004) first explored public perceptions of their original CBCP policy proposal, and Kalmanje and Kockelman (2004) examined that policy's short-term traffic and land value impacts for Austin, Texas. This paper synthesizes stakeholders' and experts' opinions and predictions of long-term system impacts to produce recommendations for a further refined CBCP policy. Academicians and practitioners in the field of transport economics, policymakers, administrators, and commercial users provided valuable feedback on issues of travel budget allocation, equity, efficiency, land use change, economic impacts, and alternative revenue uses. Toll technology experts provided recommendations for ETC technology (RFID and ANPR), system configuration, dynamic pricing issues, and variable message signs.

The revised CBCP policy proposal and associated implementation strategies aim to address stakeholders' and experts' concerns relating to the original policy proposal, including ease of implementation and use of revenues. Instead of offering cash credits to all licensed drivers in a "region," it proposes travel credits only for registered vehicle owners. Political atmosphere and financial constraints may govern if cash out will actually be allowed. Travelers with special needs can apply for additional travel credits, and net revenues can be reinvested in the transportation system. Strategies to deal with issues such as budget eligibility, visitors, enforcement, and toll collection are outlined. The paper concludes that RFID tags and ANPR may be the most appropriate technologies for implementation.

The study estimated conservative costs (including initial and recurring costs) for a $\mathrm{CBCP}$ policy implementation along Austin freeways to be about $\$ 40$ per resident when annualized. Given Austin's current modest congestion levels (relative to larger and denser metropolitan areas), the CBCP policy may not be appropriate for widespread application. However, its application at key bottleneck points, such as bridges using low-cost vehicle ID tags may make the most sense. CBCP can be a valid option for cities looking for a viable strategy to implement CP. Regions with extensive, congested transit systems may also want to examine CBCP for their road networks.

Building such a novel proposal from its theoretical foundation to everyday practice can face considerable challenges. This work strives to advance the concept and address the hurdles that can be anticipated. One of the strengths of CBCP is its flexibility. More congested systems may want to retain substantial portions of $\mathrm{CBCP}$ revenues for system enhancement. Smaller communities may opt for cashable credits rather than travel credits that expire each month. CBCP in its current form has been galvanized by expert perspectives and is now a feasible demand management strategy. It can help tackle the problem of congestion in an economically viable, equitable, and efficient fashion and, as such, is a powerful idea with significant potential. This paper will hopefully assist experts' efforts to make that potential a reality.

\section{Endnotes}

1. Of course, such a "cost” depends on the traveler's value of time, so CBD access actually should become less expensive for those who are willing to pay to avoid delays.

2. HB3588's Chapter 227 Sec. 370.174 describes the use of surplus revenue, to reduce tolls, assist in other local transportation projects, and/or deposit into the State's Mobility Fund.

3. E.g. London VES errors arose from the similarity of letter $\mathrm{O}$ and number 0 .

4. E.g. the $\mathrm{eGo}^{\mathrm{TM}} 2201$ (TransCore 2002) costs less than $\$ 10$ per tag.

5. An individual cannot have more than one account. 
6. This is calculated at an interest rate of $6 \%$ over a period of 10 years, the lifetime of the ETC system.

\section{References}

Arnott, R., A. de Palma, and R. Lindsey. "The Welfare Effects of Congestion Tolls with Heterogeneous Commuters.” Journal of Transport Economics and Policy 28, (1994): 139-161.

CityLink. CityLink Melbourne Limited, TransUrban Website, Australia. http://www.citylink.com. $\mathrm{au} /$ content/application/default.asp?CC $=26 \& C N=82$ (accessed July 21, 2004).

DeCorla-Souza, P. "FAIR lanes: A New Approach to Managing Traffic Congestion." ITS Quarterly $8(2),(2000): 5-13$.

Dial, R.B. "Minimal-Revenue Congestions Pricing Part I: A Fast Algorithm for the Single-Origin Case.” Transportation Research B 33, (1999):189-202.

Eliasson, J. and L. G. Mattsson. "Equity Effects of Congestion Pricing: Quantitative Methodology and a Case Study for Stockholm." Transportation Research Part A: Policy and Practice 40, (2006):602-620.

Gee, F.O. and H.W. Hannemann. "Pricing Road Use:Politico-Economic and Fairness Considerations.” Transportation Research Part D: Transport and Environment 7(5), (2002): 357-371.

Goodwin, P.B. "The Rule of Three: A Possible Solution to the Political Problem of Competing Objectives for Road Pricing.” Traffic Engineering and Control 29, (1989): 495-497.

Guiliano, G. "Equity and Fairness Consideration of Congestion Pricing.” In Special Report 242: Curbing Gridlock: Peak-Period Fees to Relieve Traffic Congestion, 2. Transportation Research Board, National Research Council, Washington D.C., 1994.

Kalmanje, S. and K. Kockelman. "Credit-Based Congestion Pricing: Travel, Land Value and Welfare Impacts.” Transportation Research Record 1864, (2004): 45-53.

Kockelman, K. and S. Kalmanje. "Credit-Based Congestion Pricing: A Policy Proposal and Public's Response.” Transportation Research 39A, (2005): 671-690.

New Jersey Turnpike Authority. Statement of Revenues and Expenses for the Year Ended December 31, 2003. First Consolidated Toll Road Annual Report 2003. New Jersey Turnpike Authority, 2003.

North Texas Tollway Authority. Financial Statements and Supplementary Data 2003. Dallas North Tollway System, 2003.

Orange County Transportation Authority. SR 91 Express Lanes- General Information-Toll Policy. http://www.91expresslanes.com/generalinfo/tollpolicy.asp (accessed July 26, 2004).

Parry, I.W.H. and Q. Bento. "Revenue Recycling and the Welfare Effects of Road Pricing." Scandinavian Journal of Economics 103(4), (2001): 645-647.

Small, K. “Using the Revenues from Congestion Pricing.” Transportation, (1992): 359-381.

TransCore . TransCore's eGo Products Put Electronic Toll Collection and Vehicle Registration in High Gear. http://www.transcore.com/news/news020921_2.htm (accessed July 22, 2004). 
Schrank, D. and T. Lomax. The 2003 Urban Mobility Report. Texas Transportation Institute, The Texas A\&M University, 2003.

San Joaquin Hill Transportation Corridor Agency. Statement of Revenues, Expenses and Changes in Fund Net Assets (Deficit) for the Year Ended June 30, 2003. Annual Financial Report 2003. San Joaquin, 2003.

Transport for London. Congestion Charging, 2008. http://www.tfl.gov.uk/roadusers/ congestioncharging/ (accessed February 18, 2008).

TOLLROADSnews. German GPS Truck Toll System has Big Troubles. http://tollroadsnews.info/ artman/publish/article_163.shtml (accessed August 27, 2006).

United States Census Bureau. United States Census of Population 2000. Washington, D.C. 2000.

USDOT. Unit Costs: Equipment Costs for Toll Administration (TA). U.S. Department of Transportation, Research and Innovative Technology Administration, Washington, D.C., 2000a. http://www.benefitcost.its.dot.gov/its/benecost.nsf/SubsystemCosts?OpenForm\&Subsystem=Toll+ Administration+(TA) (accessed June 20, 2004).

USDOT. Unit Costs: Equipment Costs for Toll Plaza (TP). U.S. Department of Transportation, Research and Innovative Technology Administration, Washington, D.C., 2000b. http://www. benefitcost.its.dot.gov/its/benecost.nsf/SubsystemCosts?OpenForm\&Subsystem=Toll+Plaza $+(\mathrm{TP})$ (accessed June 20, 2004).

USDOT. Urbanized Areas -2000 Selected Area Characteristics. US Department of Transportation, Washington, D.C., 2000c. http://www.fhwa.dot.gov/ohim/hs00/hm72.htm (accessed June 24, 2004).

Viegas, J.M. "Making Urban Road Pricing Acceptable and Effective: Searching for Quality and Equity in Urban Mobility.” Transport Policy, 8(4), (2201): 289-294.

\section{Acknowledgements}

We wish to thank the Texas Department of Transportation for financially supporting this study under research project \#0-4634, and Ms. Kim Limberg of the Dallas District and other project personnel for their input. We thank all the academicians and practitioners in transport economics, the policymakers, the toll technology experts, and the commercial users who responded to the survey. Thanks also go to all the people who provided valuable input that helped shape the proposed policy, and to JTRF reviewers. We thank Alexander Marks, undergraduate student researcher, for conducting the policymaker and commercial user interviews.

Pradeep Gulipalli is a modeling consultant for Marketing and Planning Systems in Waltham, Massachusetts. He holds an M.S. in civil engineering from the University of Texas at Austin.

Sukumar Kalmanje is a senior consultant with Deloitte Consulting LLP in Austin, Texas. He holds M.S. (civil engineering) and MPAff. (public affairs) degrees from the University of Texas at Austin and a B.Tech (civil engineering) degree from Indian Institute of Technology-Madras, India. Sukumar has consulting experiences in management and technology and his research interests include congestion pricing, toll roads and analysis of transportation systems using statistical and simulation techniques. 
Kara Kockelman is an associate professor of civil, architectural and environmental engineering and William J. Murray Jr. Fellow at the University of Texas at Austin, Dr. Kockelman is a registered professional engineer and holds a PhD, MS, and BS in civil engineering, a Masters of City Planning, and a minor in economics from the University of California at Berkeley. Her primary research interests include the statistical modeling of urban systems (including models of travel behavior, trade, and location choice), the economic impacts of transport policy, and transport policymaking. She has taught classes in transportation systems, transport economics, transport data acquisition and analysis, probability and statistics, and design. 